\title{
МАГНИТНО-РЕЗОНАНСНАЯ ТОМОГРАФИЯ В ДИАГНОСТИКЕ ЭНДОКРИННОЙ ОФТАЛЬМОПАТИИ
}

\author{
Бабаева Д.М., Свириденко Н.Ю., Бессмертная Е.Г., Владимирова В.П., Воронцов А.В. \\ ФГБУ «НМИЦ эндокринологии» Минздрава России, Москва
}

ЦЕЛЬ: оценить возможности применения магнитно-резонансной томографии (МРТ) в диагностике эндокринной офтальмопатии (ЭОП)

МАТЕРИАЛЫ И МЕТОДЫ: проведена МРТ 30 пациентам с ЭОП (60 орбит) на аппарате мощностью 1,5 Тл, с использованием радиочастотной катушки для исследования головного мозга. Срезы выполнены в аксиальной, корональной и сагиттальной плоскостях, в режимах Т1-взвешенные изображения (ВИ), T2-ВИ, T2 short tau inversion recovery (STIR). Получены изображения содержимого глазниц: экстраокулярные мышцы (ЭОМ), слезные железы, зрительные нервы, ретроорбитальный жир (РБК). Произведена оценка толщины и структуры ЭОМ (наличие отека, жира или фиброза), структуры слезных желез (наличие или отсутствие отека), оценка компрессии изменения зрительных нервов, РБК (отек или фиброз).

РЕЗУЛЬТАТЫ: сигнал от ЭОМ считали нормальным в случае тотального гипоинтенсивного сигнала от мышц в режиме T2 STIR. При воспалительных изменениях наблюдался гиперинтенсивный сигнал на T2 STIR и T2-BИ. При жировой дегенерации ЭОМ наблюдался повышенный сигнал на T1-ВИ и Т2-ВИ, пониженный на T2-STIR. При фиброзных изменениях наблюдаются гипоинтенсивные включения на Т1-ВИ, Т2-ВИ и T2-STIR в ЭОМ орбиты и РБК. При компрессии зрительного нерва наблюдался «симптом натяжения» зрительного нерва, при котором зрительный нерв терял свою типичную S-образную извитость.

ВЫвОды: ЭОП является тяжелым, зачастую инвалидизирующим заболеванием и для проведения ее адекватной терапии требуется тщательная оценка патологических изменений орбит. Наиболее ценными у этих пациентов являются данные, получаемые с помощью мультиспиральной компьютерной томографии (МСKT) и МРТ. МСКТ имеет свои преимущества, такие как сверхтонкие срезы, дающие хорошие возможности для мультипланарной реконструкции, короткое время исследования. В то же время, МРТ предоставляет огромные возможности оценки состояния содержимого орбиты, степени отека, жировой дистрофии и фиброза экстраокулярных мышц, слезных желез, позволяет проведение многократных исследований для динамического наблюдения, что в большинстве случае делает ее более предпочтительным методом визуализации. MPT с применением T2 STIR является наиболее чувствительным методом для оценки активности процесса ЭОП и динамики пациентов с ЭОП после глюкокортикоидной терапии. 